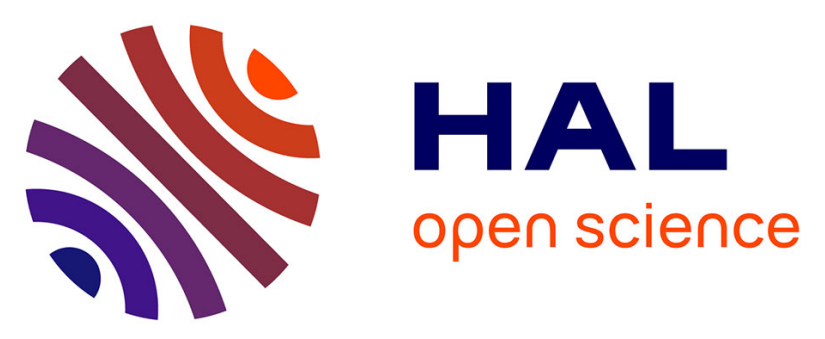

\title{
Population Pharmacokinetics and Bayesian Estimators for Refined Dose Adjustment of a New Tacrolimus Formulation in Kidney and Liver Transplant Patients
} Jean-Baptiste Woillard, Jean Debord, Caroline Monchaud, Franck Saint-Marcoux, Pierre Marquet

\section{To cite this version:}

Jean-Baptiste Woillard, Jean Debord, Caroline Monchaud, Franck Saint-Marcoux, Pierre Marquet. Population Pharmacokinetics and Bayesian Estimators for Refined Dose Adjustment of a New Tacrolimus Formulation in Kidney and Liver Transplant Patients. Clinical Pharmacokinetics, 2017, [Epub ahead of print]. 10.1007/s10928-016-9498-5 . inserm-01511054

\section{HAL Id: inserm-01511054 https://www.hal.inserm.fr/inserm-01511054}

Submitted on 20 Apr 2017

HAL is a multi-disciplinary open access archive for the deposit and dissemination of scientific research documents, whether they are published or not. The documents may come from teaching and research institutions in France or abroad, or from public or private research centers.
L'archive ouverte pluridisciplinaire HAL, est destinée au dépôt et à la diffusion de documents scientifiques de niveau recherche, publiés ou non, émanant des établissements d'enseignement et de recherche français ou étrangers, des laboratoires publics ou privés. 


\title{
HAL \\ archives-ouvertes.
}

\section{Population Pharmacokinetics and Bayesian Estimators for Refined Dose Adjustment of a New Tacrolimus Formulation in Kidney and Liver Transplant Patients}

\author{
Jean-Baptiste Woillard, Jean Debord, Caroline Monchaud, Franck \\ Saint-Marcoux, Pierre Marquet
}

\section{- To cite this version:}

Jean-Baptiste Woillard, Jean Debord, Caroline Monchaud, Franck Saint-Marcoux, Pierre Marquet. Population Pharmacokinetics and Bayesian Estimators for Refined Dose Adjustment of a New Tacrolimus Formulation in Kidney and Liver Transplant Patients. 2017.

\section{HAL Id: inserm-01511054 http://www.hal.inserm.fr/inserm-01511054}

Submitted on 20 Apr 2017

HAL is a multi-disciplinary open access archive for the deposit and dissemination of scientific research documents, whether they are published or not. The documents may come from teaching and research institutions in France or abroad, or from public or private research centers.
L'archive ouverte pluridisciplinaire HAL, est destinée au dépôt et à la diffusion de documents scientifiques de niveau recherche, publiés ou non, émanant des établissements d'enseignement et de recherche français ou étrangers, des laboratoires publics ou privés. 


\section{Population pharmacokinetics and Bayesian estimators for refined dose adjustment of a new tacrolimus formulation in kidney and in liver transplant patients}

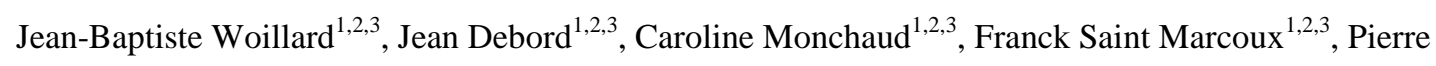
Marquet $^{1,2,3}$

1-CHU Limoges, Department of Pharmacology and Toxicology, Limoges, France; 2-INSERM UMR 850, Limoges, France; 3-Univ Limoges, France

Correspondence: Prof. P Marquet, UMR 850 INSERM, Department of Pharmacology-Toxicology, Limoges University Hospital, 87042 Limoges cedex, France.

E-mail: pierre.marquet@unilim.fr

Tel: +33555056140

Fax: +33555056162

Short title: Pharmacokinetics of a new tacrolimus formulation in kidney and in liver transplant patients

Keywords: Tacrolimus; population pharmacokinetics; non-parametric; parametric; Bayesian estimation

Acknowledgments: The authors gratefully thank Mrs. Karen Poole for manuscript editing, Veloxis and Chiesi for providing us with the phase II PK data and for funding this PK analysis. 


\section{Abstract}

Introduction: A new once-daily formulation of Tacrolimus (TAC) (Envarsus ${ }^{\circledR}$ ) has recently been developed, with alleged different pharmacokinetics from previous TAC formulations. The objectives of this study were to develop population pharmacokinetic models (POPPK) and Bayesian estimators (BE) based on limited sampling strategies (LSS) for Envarsus $®$ in kidney and in liver transplant recipients.

Material and methods: Full tacrolimus concentration-time profiles (13 samples) were drawn from 57 liver (113 profiles) and 49 kidney (97 profiles) graft recipients transplanted for at least 6 months and switched from Prograf® to Envarsus ${ }^{\circledR}$. The two databases were split into a development (75\%) and a validation (25\%) dataset. Pharmacokinetic (PK) models characterized by a single compartment with first-order elimination and absorption in two phases described by a sum of two gamma distributions were developed using non-parametric (Pmetrics®) and parametric (ITSIM $®$ ) approaches in parallel. The best limited sampling strategy for each patient group was determined using MMopt. The performance of the models and derived Bayesian estimators was evaluated in the validation set.

Results: The best LSS was $0,8 \mathrm{~h}$ and $12 \mathrm{~h}$ post-dose, leading to a relative bias \pm SD (RMSE) between observed and modelled inter-dose AUC in the validation dataset of: $0.32 \pm 6.86 \%(6.87 \%)$ for ITSIM ${ }^{\circledR}$ and $3.4 \pm 13.4 \%$ (13.2\%) for Pmetrics® in kidney transplantation; and $0.89 \pm 7.32 \%$ (7.38\%) for ITSIM ${ }^{\circledR}$ and $-2.62 \pm 8.65 \%$ (8.89\%) for Pmetrics® in liver transplantation.

Conclusion: POPPK models and BEs for Envarsus ${ }^{\circledR}$ in kidney and liver transplantation were developed and are now available online for AUC-based tacrolimus dose adjustment.

Key points: This is the first study describing the population pharmacokinetics of Envarsus ${ }^{\circledR}$, a new tacrolimus formulation, in kidney and liver transplant patients. Two modelling methods were used in parallel (a parametric and a non-parametric). Two bayesian estimators were developed enabling AUC determination using 3 samples performed at 0,8 and $12 \mathrm{~h}$ post dose. 


\section{Introduction}

Tacrolimus is the most employed first-line immunosuppressant in the prevention and treatment of allograft rejection in solid organ transplantation. As this drug has a narrow therapeutic index and significant interindividual variability, therapeutic drug monitoring (TDM) is essential to avoid under- or over-exposure [1]. Tacrolimus monitoring is routinely based on trough level measurement [2] while the average inter-dose exposure measured as the area under the curve (AUC) has been consensually recommended as the best marker for tacrolimus dose adjustment [3]. However, routine measurement of inter-dose AUC is difficult using conventional, non-compartmental methods due to the need for a large number of samples, and even more so for once-daily formulations. The a posteriori Bayesian estimation method allows estimating the inter-dose AUC using pharmacokinetic population (POPPK) models associated with a limited number of blood samples, and sometimes demographic characteristics as covariates, in individual patients. Most of the POPPK algorithms available involve a parametric approach, based on the hypothesis of a normal or log-normal distribution of the PK parameters. Pmetrics®, the R interface for NPAG (Non Parametric Adaptive Grid) proposes a nonparametric approach with no a priori hypothesis regarding the distribution of PK parameters and, while it is harder to conceptualize, it can theoretically catch outliers better than the parametric approach [4]. While the pharmacokinetics (PK) of the previously approved twice-daily (Tac BID, Prograf®) or once-daily (Tac OD, Advagraf ${ }^{\circledR}$ ) tacrolimus formulations has been well established [5,6], less is known about Envarsus ${ }$, another tacrolimus prolonged-release, once-daily formulation (Tac OD) more recently developed by Veloxis, using their patented technology MeltDose®. The registration clinical trials conducted with Envarsus® showed increased bioavailability, lower blood peak levels $(\mathrm{Cmax})$ and less peak-to-trough fluctuation at a lower total daily dose compared to Prograf ${ }^{\circledR}$ and Advagraf ${ }^{\circledR}$, both in kidney and liver transplant recipients [7-9]. Envarsus ${ }^{\circledR}$ was approved in October 2014 in Europe for "the prevention of allograft rejection in adult renal or hepatic transplant patients" and for "the treatment of allograft rejection resistant to other immunosuppressive drugs in adult patients". In 2005, we launched the ISBA (ImmunoSuppressant Bayesian dose Adjustment) website, dedicated to the estimation of inter-dose AUC and dose adjustment of immunosuppressive drugs (calcineurin inhibitors, mTor inhibitors and mycophenolate mofetil) using Bayesian estimators. Since then, more than 9200 requests for tacrolimus AUC estimation and individual dose adjustment have been received from over 64 different transplantation centres worldwide, leading to better knowledge of the drug pharmacokinetic behavior in the process [10]. Currently, no pharmacokinetic model or Bayesian estimator (BE) has been reported for the new 
Envarsus ${ }^{\circledR}$ formulation, available in Europe for both kidney and liver transplantation while, as discussed above,

PK differences are expected with respect to the Advagraf® and Prograf® formulations.

The objectives of this study were to exploit pharmacokinetic data of Envarsus® phase II studies in kidney and liver transplant recipients in order to develop POPPK models and BEs based on limited sampling strategies (LSS) using two independent modelling approaches, to be used as tools for PK-driven dose adjustment, as was previously done with the other formulations.

\section{Material and Methods}

\subsection{Patients:}

Veloxis Pharmaceuticals provided us with the individual tacrolimus blood concentration versus time data from two phase II, open label, multicentre, prospective U.S. clinical trials they conducted in stable, adult kidney and liver transplant patients, who were converted from Prograf ${ }^{\circledR}$ capsules twice-daily to Envarsus ${ }^{\circledR}$ (so-called LCPTacro at the time) tablets once-daily [7,8]. These trials complied with the declaration of Helsinki amended in Tokyo and all the patients enrolled gave their written informed consent. Data from 57 liver (113 PK profiles) and 49 kidney (97 PK profiles) graft recipients transplanted for at least 6 months and on oral maintenance immunosuppression with Prograf ${ }^{\circledR}$ were included in this PK study. After a first PK assessment on Prograf $®(7$ days after enrolment), they were switched to Envarsus ${ }^{\circledR}$ on day 8 and had two other PK assessments on days 14 and 21. At both Envarsus ${ }^{\circledR}$ PK periods, 13 blood samples were collected in EDTA tubes at pre-dose and 0.5, 1, $1.5,2,3,4,6,8,12,16,20$ and $24 \mathrm{~h}$ after dosing. The blood samples were shipped to a central laboratory for drug measurement using a validated liquid chromatography-tandem mass spectrometry (LC-MS/MS) method with a lower limit of quantitation (LLOQ) of $0.2 \mathrm{ng} / \mathrm{mL}$.

\subsection{Pharmacokinetics modelling}

Modelling was performed using in parallel two independent approaches, involving parametric (ITSIMß) and non-parametric (Pmetrics®) algorithms, respectively. Data were split into a development dataset ( $\mathrm{n}=73$ for kidney and 85 for liver) and a validation dataset ( $\mathrm{n}=24$ and 28 , respectively). Inter-occasion variability was not explored and the randomization between development and validation datasets was based on PK profiles, 
considered to be all independent from the others. A previously published structural model made of a singlecompartment with first-order elimination and one or two absorption phases described by a sum of two gamma distributions [11] that finely fitted tacrolimus profiles in renal transplantation $[12,13]$ was employed.

Briefly, the pharmacokinetic curves are described by a Gamma absorption model involving 1 or 2 absorption phases. The absorption rate at time $t$ is described by a sum of Gamma distributions:

$v_{a b s}(t)=F D \sum_{i=1}^{m} r_{i} f_{i}(t)$

with:

$f_{i}(t)=\frac{1}{\Gamma\left(a_{i}\right)} b_{i}^{a_{i}} t^{a_{i}-1} \exp \left(-b_{i} t\right)$

where $F$ denotes the bioavailability factor, $D$ the administered dose, $\Gamma$ the Gamma function, $a_{i}$ and $b_{i}$ the parameters of the distributions, $r_{i}$ the dose fraction absorbed by the $i^{\text {th }}$ way $(r 1+r 2+\ldots+r m=1)$ and $m$ the number of absorption phases.

The disposition kinetics, which corresponds to the impulse response $\mathrm{I}(\mathrm{t})$ of the system, is described by a sum of exponentials :

$I(t)=\sum_{j=1}^{p} A_{j} \exp \left(-\alpha_{j} t\right)$

This function represents the drug concentration at time $t$ after intravenous administration of a unit dose $\mathrm{D}_{0} ; \mathrm{p}$ represents the number of compartments (1 to 3 ).

The convolution of functions vabs and I yields the following expression:

$C(t)=C_{0}+F \frac{D}{D_{0}} \sum_{i=1}^{m} \sum_{j=1}^{p} r_{i} A_{j} \exp \left(-\alpha_{j} t\right)\left(\frac{b_{i}}{b_{i}-\alpha_{j}}\right)^{a_{i}} P\left[a_{i},\left(b_{i}-\alpha_{j}\right) t\right]$

Where $\mathrm{C}(\mathrm{t})$ denotes the concentration at time $\mathrm{t}, \mathrm{C}_{0}$ the residual concentration for a unit dose $(=1000 \mathrm{mg}$ for tacrolimus) and $\mathrm{P}$ denotes the incomplete Gamma function as follows:

$P(a, x)=\frac{1}{\Gamma(a)} \int_{0}^{x} z^{a-1} \exp (-z) d z$ 
A mixed (proportional and additive) error model was used with both modelling approaches. An additive (lamda) or proportional residual error (gamma) weighting the analytical error model was also investigated with Pmetrics models. Associations between the individual PK parameters and covariates (age, sex, haematocrit and time between the transplantation and inclusion in the study) were then screened using linear regression and graphical examination in the development dataset. When significant $(\mathrm{p}<0.01)$, the covariates were introduced in the model using linear, exponential or power relationships and the relevance of each covariate in the final model was assessed using its likelihood (BIC and AIC criterions). Diagnostic plots were drawn for the final models with individual predictions vs. observed concentrations and weighted residues vs. observed concentrations. The final model underwent internal evaluation using the Visual Predictive Checks. One thousand Monte-Carlo simulations were performed for a typical patient taking the median dose, and the observations were normalized by this median dose (division of concentrations by patient dose*median dose).

\subsection{Development of Bayesian estimators}

Using the population pharmacokinetic models obtained in the development datasets, the best limited-sampling strategy (LSS) among all the combinations of 3 sampling times was determined using the Multiple Model optimal (MMopt) sampling function weighted on the AUC, provided in Pmetrics®. This algorithm finds the collection times of a specified number of samples that minimize the risk of misrepresenting the patient as the wrong set of support points in the model, i.e. estimating the wrong set of PK parameters for the patient [14].

Then, the predictive performance of the Bayesian estimators developed using the best LSS was evaluated in the validation groups by comparison of the $\mathrm{AUC}_{0-24 \mathrm{~h}}$ obtained using the best 3-point LSS to the reference $\mathrm{AUC}_{0-24 \mathrm{~h}}$ obtained using the linear trapezoidal method applied to the full profiles. A calculation of the RMSE, relative bias and number of profiles out of the $\pm 20 \%$ interval compared to the reference AUC was performed. Finally, the AUCs obtained using both PK modelling approaches were compared using a Bland-Altman graph. 


\section{Results}

\subsection{Patients}

Patient characteristics from the two phase II trials are described in Table 1. The PK profiles obtained using this new formulation exhibit comparable inter-individual variability with the one reported for Prograf® in the original study reports $[7,8]$.

Observation of PK profiles showed that some exhibited one absorption phase and others two. Based on AIC criteria, the model with two gamma distributions for description of double phase absorption was retained (liver: AIC for single absorption= -11085, AIC for double-phase absorption= -11116; kidney: AIC for single absorption= -9397, AIC for double absorption= -9425).

\subsection{Model development}

A structural single-compartment model with first-order elimination and 2 absorption phases described by a sum of two gamma distributions was employed, together with a combined analytical error model of $(0.001 \mathrm{mg} / \mathrm{L}+$ concentration $\times 0.1$ ). No weighting factor (lamda or gamma) was retained with the final models as they degraded the precision of concentration and AUC estimates. The population PK parameters of the final models obtained with the two approaches in liver and kidney transplantation, as well as the model-estimated Cmax and Tmax are presented in Table 2. Interestingly, the Cmax and Tmax values were very similar whatever the type of transplantation and the PKPOP approaches with values of about $12 \mu \mathrm{g} / \mathrm{L}$ and $5 \mathrm{~h}$ respectively. The marginal densities of the PK parameters of the non-parametric models in kidney and liver transplantation are presented in Online Ressource 1. The haematocrit was significantly associated with the scale of the second gamma law $b 2=27.7-0.48 \times$ Haematocrit, $\mathrm{p}=0.00182$ ) in liver transplant patients, but its introduction in the model increased the BIC and AIC by 100 and 95 respectively, showing fit degradation rather than improvement. In kidney graft recipients, gender had a significant influence on the shape of the second gamma law $a 2=28.9-$ $6.49 \times \operatorname{sex}(1$ or 2$), \mathrm{p}=0.00074)$, but again its introduction in the model increased the BIC and AIC, by 55 and 50 respectively. None of the other covariates tested was significantly associated with any pharmacokinetic parameter, whatever the modelling approach used. The scatter plots of individually predicted versus observed concentrations showed no major bias, whatever the PK approach, and the weighted residuals were homogeneously distributed over the concentration range for both (Figure 1). The relative bias \pm SD (RMSE) between observed concentrations and concentrations estimated using the final model were: $-0.33 \pm 6.05 \%(6.05 \%)$ 
for ITSIM® and $0.34 \pm 9.22 \%(9.22 \%)$ for Pmetrics® in liver transplantation; $-0.57 \pm 7.38 \%(7.40 \%)$ and $0.64 \pm 9.46 \%(9.48 \%)$ in kidney transplantation, respectively. The model was then evaluated using the visual predictive checks (VPC). The observed data normalized to a dose of $5 \mathrm{mg}$ (median) overlaid adequately the $90 \%$ prediction intervals of the simulations for both kidney and liver transplantation groups and both POPPK approaches (Figure 2).

\subsection{Bayesian estimators}

The optimal sampling times proposed by the MMopt algorithm were $0,8 \mathrm{~h}$ and $12 \mathrm{~h}$ post-dose for both kidney and liver transplant groups. The Bayesian estimators derived from each of the POPPK models and based on this $0,8 \mathrm{~h}$ and $12 \mathrm{~h}$ sampling schedule yielded accurate estimation of $\mathrm{TAC} \mathrm{AUC}_{0-24 \mathrm{~h}}$ in the validation dataset (Table 3). Random examples of profiles modelled using each method in kidney and liver transplantation are presented in Figure 3. The bias and RMSE were always lower with ITSIM $®$, as was the number of poorly estimated AUCs. Finally, the Bland-Altman plots of the differences between the 3-point AUC estimates obtained with Pmetrics® and ITSIM $®$ are presented in Figure 4, separately for liver and kidney transplant patients, showing up to $50 \%$ difference in a few cases (mean difference \pm SD (min;max): kidney=-0.005 $\pm 0.038(-0.112 ; 0.0802) \mathrm{mg} * \mathrm{~h} / \mathrm{L}$; and liver $=0.008 \pm 0.020(-0.015 ; 0.095) \mathrm{mg} * \mathrm{~h} / \mathrm{L})$. It corresponded to one difference out of the $95 \%$ confidence interval in liver transplant patients and 2 in kidney transplant patients (1 above the upper limit and 1 below the lower limit of the $95 \%$ confidence interval).

\section{Discussion}

In this study ancillary to two phase II clinical trials of the new once-daily, prolonged-release tacrolimus formulation Envarsus ${ }^{\circledR}$, one in liver and one in kidney stable adult transplant recipients, we developed POPPK models and Bayesian estimators with their corresponding best limited sampling strategy, in order to accurately estimate tacrolimus $\mathrm{AUC}_{0-24 \mathrm{~h}}$ using only 3 blood samples. These models and estimators were developed using in parallel two independent POPPK approaches, one parametric developed in-house and used for the expert system ISBA (https://pharmaco.chu-limoges.fr), and the other a shareware characterized by its non-parametric approach (http://www.lapk.org/pmetrics.php). As expected, the coefficients of variation of the PK parameters obtained using the non-parametric approaches were wider, which is consistent with the fact that non-parametric modelling is based on the discrete probability of each parameter rather than on the assumption of their normal distribution $[15,16]$. Similarly, the individual prediction $v s$. observed concentration graph showed 3 outliers with ITSIM ${ }^{\circledR}$ that were not observed with Pmetrics ${ }^{\circledR}$. Two of them corresponded to highest concentrations observed at the 
peak in a single kidney transplant recipient. Although the parametric model underestimated in some patients the first peak, the AUCs were well estimated in most cases, with only few patients out of the $\pm 20 \%$ interval when comparing estimated and reference AUCs. However, in this study the bias and RMSE of AUC estimates obtained with ITSIM ${ }^{\circledR}$ were smaller than those with Pmetrics®, especially in kidney transplant recipients. The AUC differences between the 2 approaches were generally acceptable, although they reached almost $50 \%$ in a few cases (Figure 4). However, combining 2 independent modelling approaches may allow decreasing the error in AUC estimation, especially in the case of discordant results as previously shown for MMF in heart transplant patients [17] or cyclosporine in hematopoietic stem cell transplant patients [18].

Very interestingly, the pharmacokinetic parameters obtained here using ITSIM $®$ in kidney transplant patients are significantly different (t-test) compared to those previously obtained using exactly the same model in another population of kidney transplant recipients for the other once-daily tacrolimus formulation Advagraf® [13]. As a consequence, while we were able to propose a convenient and efficient LSS within the first 3 hours post-dose $(0$, $1 \mathrm{~h}$ and $3 \mathrm{~h}$ ) for Advagraf $\circledast$ ), all the convenient limited sampling strategies for Envarsus $®$ included later sampling times, the best being $0,8 \mathrm{~h}$ and $12 \mathrm{~h}$. This LSS is more difficult to apply in routine practice, but dried blood spot sampling by patients at home is increasingly employed [19], which should render this LSS and $\mathrm{AUC}_{0-24 \mathrm{~h}}$ Bayesian estimation feasible. Of note, population pharmacokinetics and Bayesian estimation are flexible with respect to sampling times, meaning that even if samples are taken at (slightly) different times than those scheduled and on condition that the exact times are known, the inter-dose AUC can still be estimated accurately.

This study has however some limitations. First, it was a switch study that was performed in stable kidney and liver transplant recipients more than 6 months after transplantation. Due to the changes in tacrolimus clearance, the model and LSS developed here may not be applicable in patients receiving tacrolimus-Envarsus ${ }^{\circledR}$ de novo. Secondly, only few covariates and especially no pharmacogenetic data were available (in particular for the CYP3A5 and CYP3A4 genotypes). The influence of CYP3A5 on tacrolimus clearance and trough level is well established [20]. However, covariates are most useful in cases of simulation, or for estimating the first dose to be given to individual patients, i.e. only when no a posteriori data are available. In case of Bayesian estimation using a LSS, most of the information is carried by the a posteriori data (i.e. concentrations) themselves if they are in sufficient number (i.e. a CYP3A5 expressor will have lower concentrations than a non-expressor). In this case, covariates will lead to an increase in the number of parameters to estimate, which may be of limited benefit in terms of accuracy, as is obviously the case here. 
In conclusion: POPPK models and BEs for Envarsus ${ }^{\circledR}$ in adult kidney or liver transplant patients have been developed to help clinicians individualize the drug dose The tools developed with ITSIM® are now available on the ISBA website (https://pharmaco.chu-limoges.fr), while those developed with Pmetrics® can be provided for research purposes upon request. 


\section{References}

1. Venkataramanan R, Swaminathan A, Prasad T, Jain A, Zuckerman S, Warty V, et al. Clinical pharmacokinetics of tacrolimus. Clin. Pharmacokinet. 1995;29:404-30.

2. Laskow DA, Vincenti F, Neylan JF, Mendez R, Matas AJ. An open-label, concentration-ranging trial of FK506 in primary kidney transplantation: a report of the United States Multicenter FK506 Kidney Transplant Group. Transplantation. 1996;62:900-5.

3. Wallemacq P, Armstrong VW, Brunet M, Haufroid V, Holt DW, Johnston A, et al. Opportunities to optimize tacrolimus therapy in solid organ transplantation: report of the European consensus conference. Ther. Drug Monit. 2009;31:139-52.

4. Neely MN, van Guilder MG, Yamada WM, Schumitzky A, Jelliffe RW. Accurate detection of outliers and subpopulations with Pmetrics, a nonparametric and parametric pharmacometric modeling and simulation package for R. Ther. Drug Monit. 2012;34:467-76.

5. Staatz CE, Willis C, Taylor PJ, Tett SE. Population pharmacokinetics of tacrolimus in adult kidney transplant recipients. Clin. Pharmacol. Ther. 2002;72:660-9.

6. Staatz CE, Tett SE. Clinical Pharmacokinetics of Once-Daily Tacrolimus in Solid-Organ Transplant Patients. Clin. Pharmacokinet. 2015;54:993-1025.

7. Gaber AO, Alloway RR, Bodziak K, Kaplan B, Bunnapradist S. Conversion from twice-daily tacrolimus capsules to once-daily extended-release tacrolimus (LCPT): a phase 2 trial of stable renal transplant recipients. Transplantation. 2013;96:191-7.

8. Alloway RR, Eckhoff DE, Washburn WK, Teperman LW. Conversion from twice daily tacrolimus capsules to once daily extended-release tacrolimus (LCP-Tacro): phase 2 trial of stable liver transplant recipients. Liver Transpl. 2014;20:564-75.

9. Tremblay S, Nigro V, Weinberg J, Woodle ES, Alloway RR. A Steady-State Head-to-Head Pharmacokinetic Comparison of All FK-506 (Tacrolimus) Formulations (ASTCOFF): An Open-Label, Prospective, Randomized, Two-Arm, Three-Period Crossover Study. Am. J. Transplant. 2016; 
10. Saint-Marcoux F, Woillard J-B, Jurado C, Marquet P. Lessons from routine dose adjustment of tacrolimus in renal transplant patients based on global exposure. Ther. Drug Monit. 2013;35:322-7.

11. Prémaud A, Debord J, Rousseau A, Le Meur Y, Toupance O, Lebranchu Y, et al. A double absorption-phase model adequately describes mycophenolic acid plasma profiles in de novo renal transplant recipients given oral mycophenolate mofetil. Clin. Pharmacokinet. 2005;44:837-47.

12. Saint-Marcoux F, Knoop C, Debord J, Thiry P, Rousseau A, Estenne M, et al. Pharmacokinetic study of tacrolimus in cystic fibrosis and non-cystic fibrosis lung transplant patients and design of Bayesian estimators using limited sampling strategies. Clin. Pharmacokinet. 2005;44:1317-28.

13. Saint-Marcoux F, Debord J, Undre N, Rousseau A, Marquet P. Pharmacokinetic modeling and development of Bayesian estimators in kidney transplant patients receiving the tacrolimus once-daily formulation. Ther. Drug Monit. 2010;32:129-35.

14. Neely M, Philippe M, Rushing T, Fu X, van Guilder M, Bayard D, et al. Accurately Achieving Target Busulfan Exposure in Children and Adolescents With Very Limited Sampling and the BestDose Software. Ther. Drug Monit. 2016;38:332-42.

15. Bustad A, Terziivanov D, Leary R, Port R, Schumitzky A, Jelliffe R. Parametric and nonparametric population methods: their comparative performance in analysing a clinical dataset and two Monte Carlo simulation studies. Clin. Pharmacokinet. 2006;45:365-83.

16. Prémaud A, Weber LT, Tönshoff B, Armstrong VW, Oellerich M, Urien S, et al. Population pharmacokinetics of mycophenolic acid in pediatric renal transplant patients using parametric and nonparametric approaches. Pharmacol. Res. 2011;63:216-24.

17. Woillard J-B, Saint-Marcoux F, Monchaud C, Youdarène R, Pouche L, Marquet P. Mycophenolic mofetil optimized pharmacokinetic modelling, and exposure-effect associations in adult heart transplant recipients. Pharmacol. Res. 2015;99:308-15.

18. Woillard J-B, Lebreton V, Neely M, Turlure P, Girault S, Debord J, et al. Pharmacokinetic tools for the dose adjustment of ciclosporin in haematopoietic stem cell transplant patients. Br. J. Clin. Pharmacol. 2014;78:83646. 
19. Koop DR, Bleyle LA, Munar M, Cherala G, Al-Uzri A. Analysis of tacrolimus and creatinine from a single dried blood spot using liquid chromatography tandem mass spectrometry. J. Chromatogr. B Analyt. Technol. Biomed. Life. Sci. 2013;926:54-61.

20. Hesselink DA, Bouamar R, Elens L, van Schaik RHN, van Gelder T. The role of pharmacogenetics in the disposition of and response to tacrolimus in solid organ transplantation. Clin. Pharmacokinet. 2014;53:123-39. 
Table1-Characteristics of the kidney or liver transplant recipients

\begin{tabular}{|c|c|c|}
\hline & Kidney & Liver \\
\hline Age (years) & $50(22-66)$ & $52(20-66)$ \\
\hline Sex (M/F) & $35 / 14$ & $32 / 25$ \\
\hline Tacrolimus dose (mg) & $4(1-16)$ & $39.6(30.2-49)$ \\
\hline Hematocrit (\%) on day & $41.5(31.2-54.0)$ & $2.68(0.56-14.25)$ \\
\hline Transplantation (years) & $2.05(0.50-8.70)$ & $70(25-123)$ \\
\hline GFR* at baseline & $56(32-104)$ & \\
ml/min/1.73m & & \\
\hline$\mu($ SD)Median (range), $*$
\end{tabular}

Disease (MDRD7) equation in both studies 
Table 2- PK parameters of Envarsus ${ }^{\circledR}$ obtained using parametric (ITSIM $\left.®\right)$ and non-parametric (Pmetrics $\left.{ }^{\circledR}\right)$ approaches in liver and kidney transplantation.

\begin{tabular}{|c|c|c|c|c|}
\hline & \multicolumn{2}{|c|}{ Kidney } & \multicolumn{2}{|c|}{ Liver } \\
\hline & ITSIM & Pmetrics & ITSIM & Pmetrics \\
\hline $\mathrm{CO}(\mathrm{mg} / \mathrm{L})^{*}$ & $1.7(0.3-5.2)$ & $1.7(0.3-4.9)$ & $1.3(0.3-3.4)$ & $1.4(0.4-3.4)$ \\
\hline FAIV $(\mu g / L)$ & $2.8(0.7-6.1)$ & $2.3(0.5-9.9)$ & $2.6(34 \%)$ & $2.0(0.7-19.1)$ \\
\hline A1 & $7.9(1.0-23.3)$ & $19.4(1.2-39.8)$ & $5.2(1.0-11.9)$ & $27.2(4.2-49.7)$ \\
\hline B1 $\left(h^{-1}\right)$ & $5.6(1.2-11.0)$ & $5.9(0.2-29.8)$ & $5.5(1.8-12.8)$ & $5.5(0.3-48.7)$ \\
\hline A2 & $13.8(1.0-33.8)$ & $20.7(4.3-39.8)$ & $14.3(4.1-30.9)$ & $20.8(1.2-49.7)$ \\
\hline B2 $\left(h^{-1}\right)$ & $2.3(0.3-5.7)$ & $6.8(0.8-29.8)$ & $2.9(0.6-7.3)$ & $8.6(0.5-29.8)$ \\
\hline $\mathbf{r}$ & $0.4(0.0-1.0)$ & $0.6(0.0-0.9)$ & $0.21(0.0-0.64)$ & $0.62(0.11-0.99)$ \\
\hline$\alpha\left(\mathbf{h}^{-1}\right)$ & $0.17(0.05-0.45)$ & $0.15(0.01-0.99)$ & $0.18(0.05-0.43)$ & $0.18(0.02-1.49)$ \\
\hline $\operatorname{Cmax}(\mu \mathrm{g} / \mathrm{L})$ & $12.1(5.4-31.5)$ & $12.4(5.4-39.6)$ & $11.7(3.70-30.6)$ & $12.5(4.2-29.5)$ \\
\hline $\operatorname{Tmax}(h)$ & $6.3(1.3-12.7)$ & $5.4(1.0-10.2)$ & $5.5(1.2-15.0)$ & $5.6(0.8-20.2)$ \\
\hline
\end{tabular}

Median (min-max); a1, b1, a2, b2 are the shape and scale of the two gamma functions, $r$ is the fraction of dose absorbed following the first gamma function, $* \mathrm{C} 0$ is the model estimated trough level for a theoretical dose of $1000 \mathrm{mg}$ (the real trough level can be calculated by dividing this value by 1000 and multiplying by the patient dose), FAIV is the estimated, absolute bioavailability factor with respect to the IV route and $\alpha$ is the elimination parameter. Cmax (the maximum concentration) and Tmax (time of the maximum concentration) were estimated from the fitted pharmacokinetic profiles. 
Table 3- AUC estimation performance of the Bayesian estimators based on the $0,8 \mathrm{~h}$ and $12 \mathrm{~h}$ limited sampling strategy in the validation datasets.

\begin{tabular}{|c|c|c|c|c|}
\hline & \multicolumn{2}{|c|}{ kidney } & \multicolumn{2}{|c|}{ liver } \\
\hline & ITSIM@ & Pmetrics ${ }^{\circledR}$ & ITSIM@ & Pmetrics ${ }^{\circledR}$ \\
\hline RMSE (\%) & 6.87 & 13.22 & 7.38 & 8.89 \\
\hline Relative bias \pm SD $(\%)$ & $0.32 \pm 6.86$ & $3.4 \pm 13.01$ & $0.89 \pm 7.32$ & $-2.62 \pm 8.65$ \\
\hline $\begin{array}{l}\text { Number of profiles out of } \\
\text { the } \pm 20 \% \text { interval }\end{array}$ & $1 / 24$ & $2 / 24$ & $0 / 28$ & $2 / 28$ \\
\hline
\end{tabular}




\section{List of Figures}

Figure 1- Diagnostic plots: individual predicted concentrations for ITSIM $₫$ and Pmetrics $₫$ as function of observed concentrations in kidney transplant patients (A and B, resp.) and in liver transplant patients (C and D, resp.); and weighted residuals with ITSIM $®$ and Pmetrics ${ }^{\circledR}$ as function of observed concentrations in kidney transplant patients (E and F, resp.) and in liver transplant patients ( $\mathrm{G}$ and $\mathrm{H}$, resp.)

Figure 2- Visual predictive check based on a normalized dose of $5 \mathrm{mg}$ in kidney transplant recipients for $\operatorname{ITSIM} ®(A)$ and Pmetrics ${ }^{\circledR}(B)$ and in liver transplant recipients for ITSIM $®(C)$ and Pmetrics $($ D)

Figure 3- Random examples of individual profiles for ITSIM® and Pmetrics®, in kidney (A and B, resp.) and in liver transplant patients ( $\mathrm{C}$ and $\mathrm{D}$, resp.). The black lines are the model predicted curve and the grey line are the observed datas.

Figure 4- Bland-Altman plot of the differences between the 3-point AUC estimates obtained using ITSIM® and Pmetrics®. 

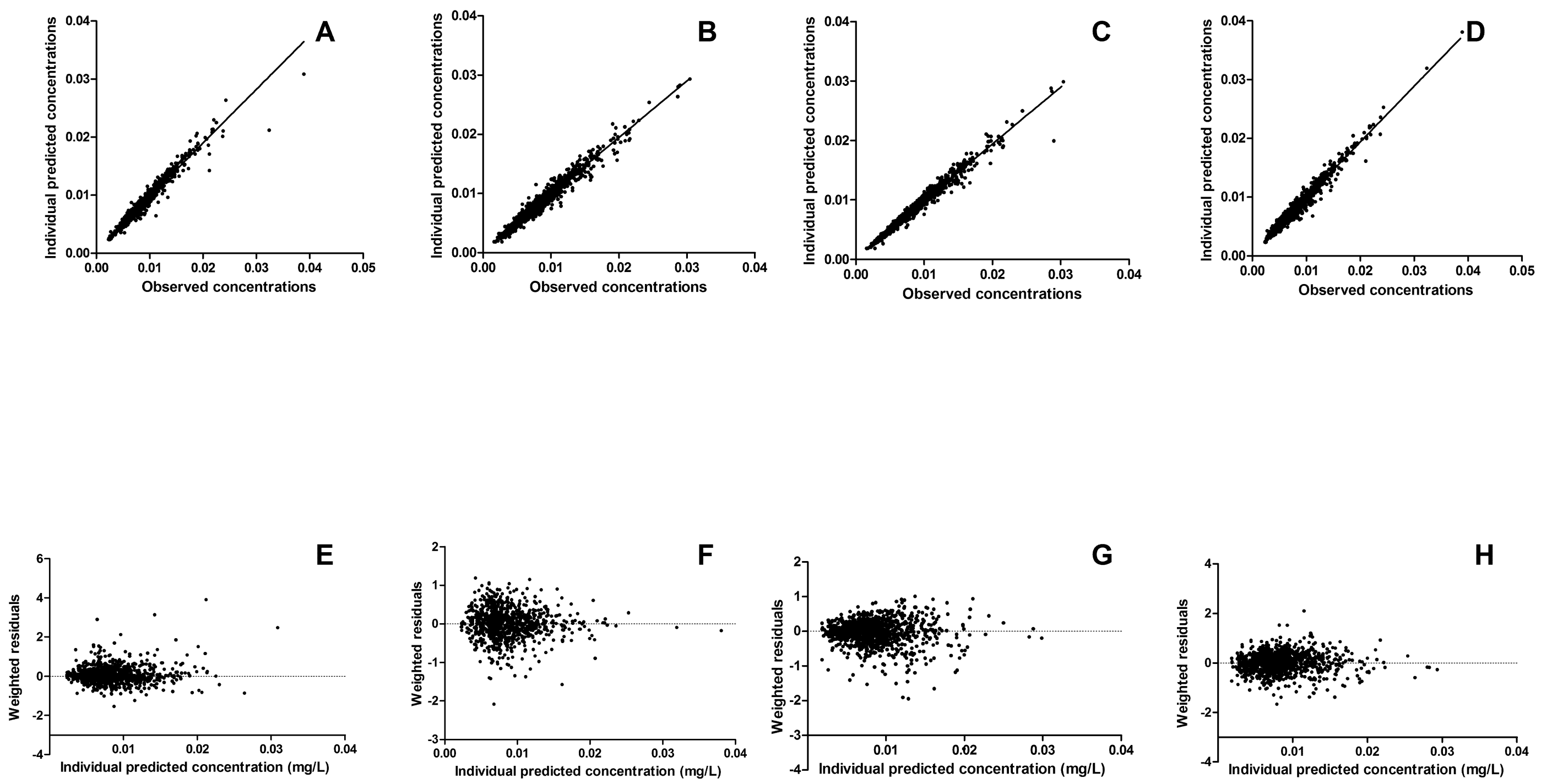


\section{Liver}

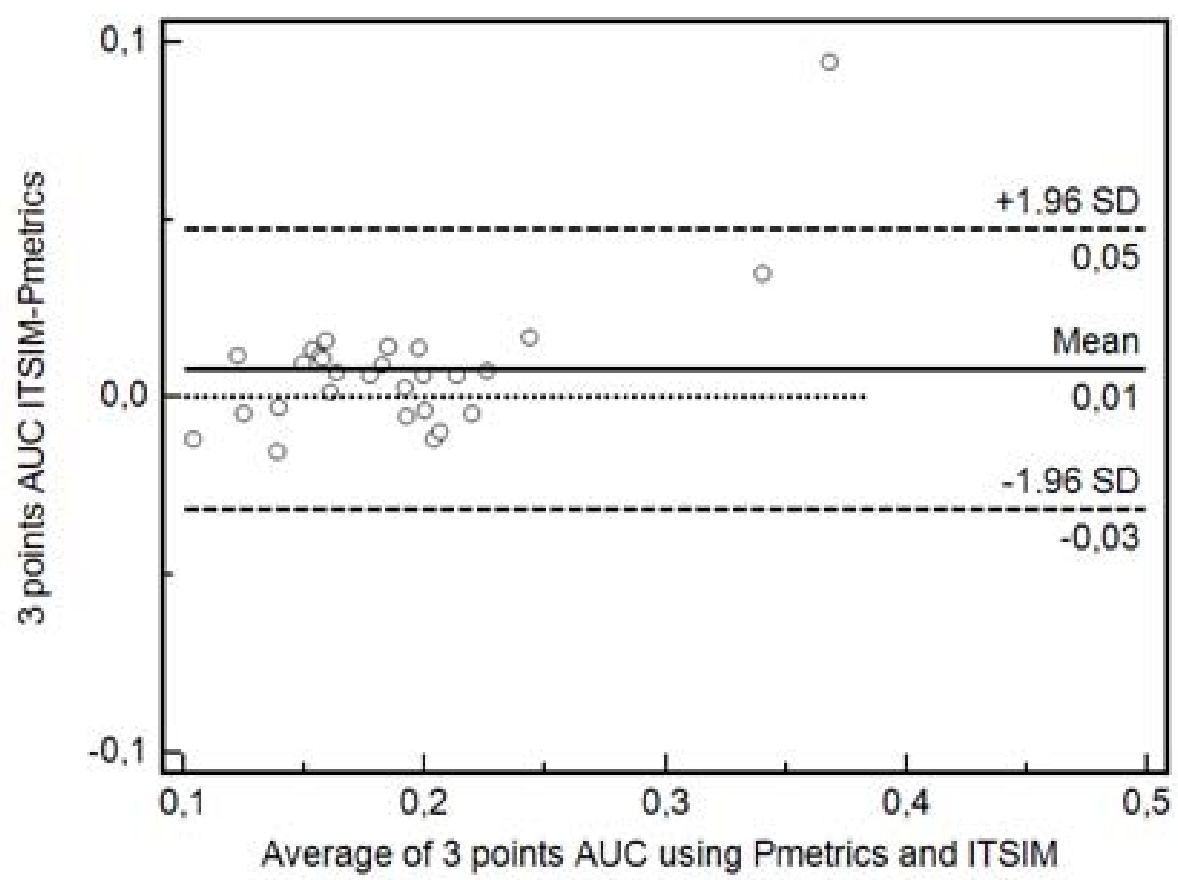

Kidney

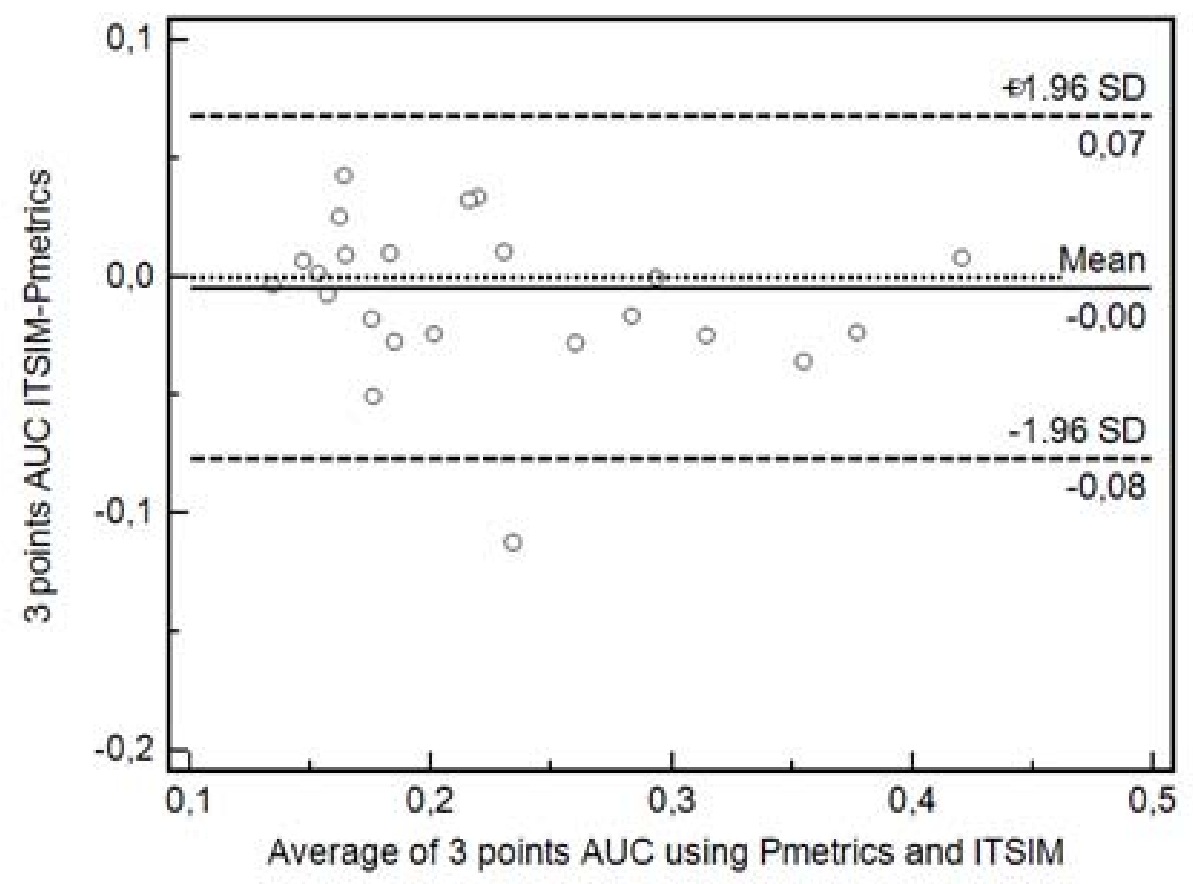



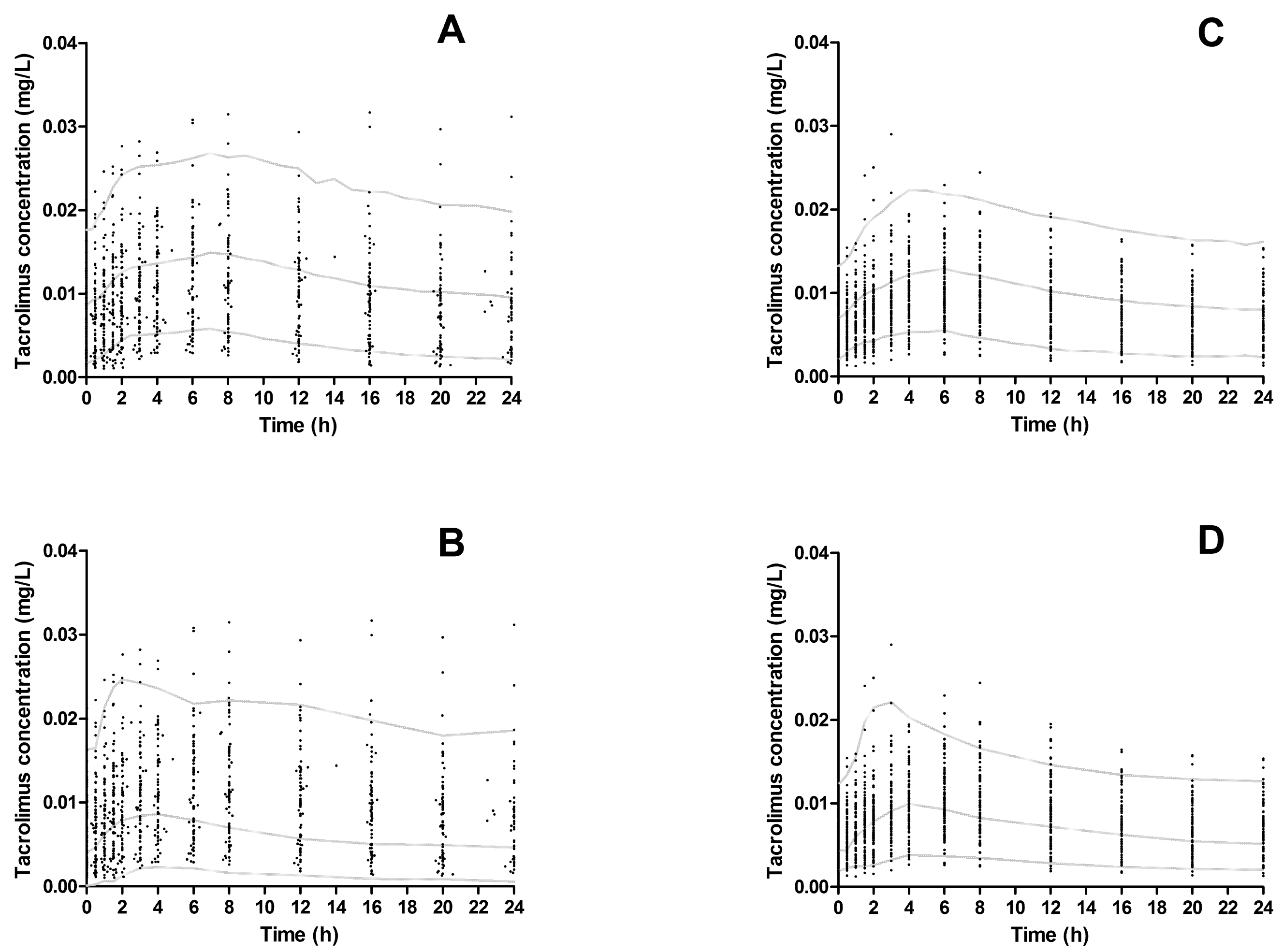